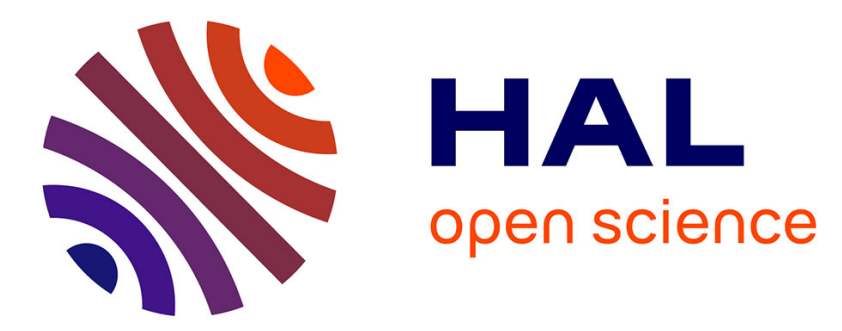

\title{
Long-run equilibrium in international assets and goods markets: Why is the Law of One Price required?
}

\author{
Stefano Bosi, Patrice Fontaine, Cuong Le Van
}

\section{To cite this version:}

Stefano Bosi, Patrice Fontaine, Cuong Le Van. Long-run equilibrium in international assets and goods markets: Why is the Law of One Price required?. Journal of Economic Behavior and Organization, 2021, 190, pp.891-904. 10.1016/j.jebo.2021.08.023 . hal-03330856

\section{HAL Id: hal-03330856 https://hal.science/hal-03330856}

Submitted on 3 Jan 2022

HAL is a multi-disciplinary open access archive for the deposit and dissemination of scientific research documents, whether they are published or not. The documents may come from teaching and research institutions in France or abroad, or from public or private research centers.
L'archive ouverte pluridisciplinaire HAL, est destinée au dépôt et à la diffusion de documents scientifiques de niveau recherche, publiés ou non, émanant des établissements d'enseignement et de recherche français ou étrangers, des laboratoires publics ou privés. 


\title{
Long-run equilibrium in international assets and goods markets: Why is the Law of One Price required?*
}

\author{
Stefano BOSI $^{\dagger} \quad$ Patrice FONTAINE ${ }^{\ddagger} \quad$ Cuong LE VAN ${ }^{\S}$
}

February 14, 2021

\begin{abstract}
Globalization is a complex phenomenon, best represented by a general framework in which all financial markets and some goods markets adjust quickly, while for the other goods markets prices vary across countries. We consider a two-period financial model. In the first period, agents consume, buy and sell financial assets to diversify their portfolios. In the second period, they spend their endowments and financial gains to purchase consumption goods. We define the concept equilibrium*, in which the total nominal value of trade is balanced and, for any non-negative individualized system of prices, the total nominal value of demand does not exceed the total value of supply. This equilibrium* coincides with the standard concept of equilibrium when the Law of One Price (LOP) is satisfied for any country. In this model, we introduce imperfect international trade. Assuming that Uncovered Interest (rate) Parity (UIP) holds in all financial markets and the LOP does not hold in some goods markets, we prove that an equilibrium* does exist; for markets in which the LOP fails, however, the equilibrium becomes autarkic. This result explains why financial markets and some goods markets are globally integrated, while trade fails in other markets. The world economy is fully globalized only if the LOP holds everywhere.
\end{abstract}

Keywords: general equilibrium, no arbitrage, returns on financial assets, Law of One Price, Uncovered Interest (rate) Parity.

JEL Classification: D53, F31, G11, G15.

\section{Introduction}

Globalization is characterized by increasing international trade, knowledge dissemination, and cultural intermingling. From an economic standpoint, we observe a higher mobility of

\footnotetext{
*The authors acknowledge the financial support of the project FIRE (ANR-15-CE33-0001).

†Université Paris-Saclay, Univ Evry, EPEE, 91025, Evry-Courcouronnes, France. E-mail: stefano.bosi@universite-paris-saclay.fr.

${ }^{\ddagger}$ CNRS (EUROFIDAI), Léonard de Vinci Pôle Universitaire.

${ }^{\S}$ IPAG Business School, PSE, CNRS, TIMAS, CASED, DEPOCEN.
} 
goods, capital, and labor, resulting in price alignment across countries. Not all markets behave the same way, however. The integration of financial markets reduces the opportunity for arbitrage, which means interest rate expectations align under the same probability distribution around the globe (Bosi et al. (2016)). Goods markets are more heterogeneous. Non-tradable goods have local prices, while the prices of internationally traded goods adjust more or less quickly depending on trade barriers and other frictions in the market. In the absence of trade barriers, as in the case of the World Trade Organization, goods have the same prices everywhere.

Two strands of literature address these aspects of globalization. The financial literature refers (after adjustment for exchange rates) to nominal returns equalization as Uncovered Interest (rate) Parity (UIP), while the literature on international trade refers to equal prices (adjusted for exchange rates) across countries in terms of the Law of One Price (LOP). Let us explore these two distinct approaches.

The LOP claims that the prices of commodities expressed in the same unit of account are equal all over the world. Tests by Protopapadakis and Stoll (1986) support this assertion in the long run, but reject the LOP in the short run. Likewise, Pippenger and Phillips (2008) show "how four common pitfalls cause cointegration tests to reject the LOP" and conclude that there is no reliable evidence contradicting the law.

UIP is a condition of no arbitrage in the financial assets markets, connecting interest and exchange rates. ${ }^{1}$ Again, UIP asserts that any interest rate in currency $i$ equals the sum of the interest rate in currency $j$ and the difference between the exchange rates. ${ }^{2}$ In some studies, however, UIP refers to the equalization of returns across countries in expectation, not state by state. To clarify the discussion, Bosi et al. (2016) introduce a formal definition of equalization in expectation, referred to as Weak Uncovered Interest (rate) Parity (WUIP): i.e., there exists a common probability distribution, such that the expectations of the returns of the countries are equal. Obviously, UIP implies WUIP.

A number of empirical studies reject UIP in the short run, pointing out both the portfolio home bias and the risk premium. Sarno et al. (2012) and Hassan and Mano (2017), for example, focus on the role of the foreign exchange risk premium in UIP failure. Martin (2013) and Hassan (2013) connect the risk premium to the country size, while Lewis (2011)

\footnotetext{
${ }^{1}$ Some authors use the name of LOP for UIP. This introduces confusion because as people often think that, when UIP is satisfied, the LOP is verified as well: see for instance Lamont et al. (2003) and Akram et al. (2008). Bosi et al. (2016) show that, at equilibrium, UIP implies the LOP if only one consumption good is considered, and that the LOP becomes equivalent to the UIP if, in addition, there is no uncertainty. In the present paper, we consider many consumption goods.

${ }^{2}$ Indeed, let $r_{s}^{i}$ denote the interest rate in country $i$. Let $\tau_{s}^{i}$ be the exchange rate of country $i$ (the exchange rate of country $j$ is normalized to 1$)$ and $\sigma_{s}^{i} \equiv \tau_{s}^{i}-1$ be the difference between exchange rates. Under the UIP, we have $1+r_{s}^{i}=\left(1+r_{s}^{j}\right) \tau_{s}^{i}=\left(1+r_{s}^{j}\right)\left(1+\sigma_{s}^{i}\right)$. Thus, $r_{s}^{i}$ is approximately equal to $r_{s}^{j}+\sigma_{s}^{i}$. See Bosi et al. (2017) for more details.

${ }^{3}$ Two markets are not integrated if it is possible to construct two portfolios, one from each market, that have identical payoffs but different prices, while these markets are said to be perfectly integrated if the LOP holds across them. Notice that the LOP these authors refer to concerns the portfolios prices instead of the prices of goods. They introduce two measures of pricing discrepancy between markets focused on the LOP (weak measure) and on the LOP and a lack of cross-market arbitrage opportunities (strong measure). According to their estimations, NYSE and NASDAQ are closely integrated in the weak but not in the strong sense.
} 
associates the risk factors with local monetary and fiscal policies.

The question of equalization of returns across countries in the long run remains controversial, but Akram et al. (2008) find that it holds on average. Isard (2006) observes that "although the empirical evidence strongly rejects the unbiasedness hypothesis at prediction horizons of up to one year, the evidence is much more favorable to unbiasedness at horizons of five to twenty years."

Theoretically, globalization with heterogeneous markets should be represented by a general equilibrium model in which all financial markets and some goods markets adjust quickly, while, for other markets, prices vary across countries. In other words, to draw a realistic picture of globalization with all its imperfections, we assume that UIP holds for all financial markets, while the LOP holds only for some goods markets. The remaining goods markets have local or "individualized" prices under the assumption of one representative agent per country.

We introduce these incomplete international markets into a two-period financial model inspired by Hart (1974). ${ }^{4}$ In the first period, agents buy or sell financial assets to diversify their portfolios. In the second period, they buy consumption goods, spending their endowments and financial gains. These gains are the returns on the financial assets the agents receive in each state.

Our approach, which avoids any confusion between the different notions of parity, can be justified on the empirical grounds:

(1) we make a clear difference between UIP, as a link between the interest and exchange rates, and the LOP, as a link between commodity prices and exchange rates (as shown above, this difference matters when there is more than one consumption good) $;^{5}$

(2) to avoid the problem of non-observable expectations of exchange rates, as pointed out by Isard (2006), we assume that, in the long run, UIP holds state by state, i.e., that our returns matrices (and, hence, the exchange rates) also depend on the state;

(3) we rely on the conclusions of Protopapadakis and Stoll (1983) to justify the assumption of the LOP for some markets, but not for all.

We call markets "globalized" where the LOP holds. At equilibrium, these markets experience a balance of trade. We introduce the notion of equilibrium* for the other markets, where trade barriers or other market frictions impede trading. At equilibrium*, the total nominal value of trade is balanced and, for any non-negative individualized system of prices, the total nominal value of demand does not exceed the total value of supply. This condition may seem demanding, but is, in fact, reasonable from an economic standpoint.

Under UIP, when the LOP holds in any market, equilibrium and equilibrium* coincide. In this respect, our definition of equilibrium* is quite ordinary and is suitable for use in the standard Arrow-Debreu general equilibrium framework. While we prove the existence of equilibrium*, however, we find that every equilibrium is not necessarily an equilibrium*. When the LOP fails, in addition, any equilibrium* will be partially autarkic. ${ }^{6}$

\footnotetext{
${ }^{4}$ The markets are complete when the rank of the returns matrix equals the number of states of nature. In particular, they are complete when the number of states equals the number of assets and assets are not redundant, and they are incomplete when the number of states is larger than the number of financial assets.

${ }^{5}$ Bosi et al. (2016) prove that, with a single consumption good and returns given in terms of this good, at equilibrium, UIP implies the LOP. In the present paper, we consider many consumption goods.

${ }^{6}$ Obstfeld and Rogoff (2000) stress the impact of trade frictions: "Costs of international trade can dra-
} 
This result explains how financial markets and some goods markets can be integrated, but trade fails in other markets. In the theoretical literature, failure of the LOP is often explained by introducing shipping costs or other trade frictions (see Obstfeld and Rogoff (2000), among others). In frictionless markets, failure of the LOP intuitively leads to autarky because, otherwise, some agent would exploit the arbitrage opportunity (Remark 4(c)). In our model, however, we show that we do not need to introduce trade costs, but can instead prove the autarkic issue through a general equilibrium mechanism.

Our paper is organized as follows. In Sections 2 to 4, we present the model and the main definitions and assumptions. Section 5 is devoted to the case of nominal assets where returns are expressed in a currency as the unit of account, while section 6, to takes on the case of real assets where returns are expressed in terms of a physical good as the unit of account. Section 7 concludes, justifying the assumptions of UIP and the LOP on the grounds of the current empirical literature. All the proofs are gathered in the Appendix (Section 8).

\section{Model}

We consider a two-period model with $I$ countries indexed by $i$. In the first period, as in usual incomplete markets models, the representative agent of each country purchases $L$ consumption goods ${ }^{7}$ and a vector of $J$ assets $z^{i} \in \mathbb{R}^{J}$ at the prices $q \in \mathbb{R}^{J}$. Each agent $i$ has an endowment $\omega_{0}^{i} \in \mathbb{R}_{+}^{L}$. In the second period, there are $S$ states of nature. In the state $s$, each representative agent of country $i$ receives a vector of $L$ endowments $\omega_{s}^{i} \in \mathbb{R}_{+}^{L}$ and a vector of $J$ returns $R_{s}^{i} \in \mathbb{R}_{+}^{J}$. Spending these revenues, she buys a vector of $L$ consumption goods $x_{s}^{i} \in \mathbb{R}_{+}^{L}$ at the prices $p_{s}^{i} \in \mathbb{R}^{L}$.

In the following analysis, the price vectors $q$ and $p_{s}^{i}$, and the return vector $R_{s}^{i}$ will be considered as rows, while the quantity vectors $z^{i}, \omega_{s}^{i}$ and $x_{s}^{i}$ are columns. The rows $R_{s}^{i}$ form an $S \times J$ matrix of returns denoted $R$. For simplicity, $\sum_{i}, \sum_{j}, \sum_{s}$ will replace the cumbersome notation $\sum_{i=1}^{I}, \sum_{j=1}^{J}, \sum_{s=1}^{S}$, while $\left(x_{s}^{i}\right)_{s}$ will replace the sequence $\left(x_{1}^{i}, \ldots, x_{S}^{i}\right)$. The same will hold for the other variables.

UIP and LOP need to compare in the same unit of account the prices of the goods, the prices and the returns of the financial assets.

The unit of account can be any currency $i$ or any physical good $l$. When UIP and LOP are respected, the prices and returns are equal, whatever the used unit of account.

We will consider two cases:

(1) the prices $q_{j}$ and $p_{s}^{i}$, and the returns $R_{s j}^{i}$ are all expressed in the same unit of account (for instance, currency $i$ );

(2) the prices $q_{j}$ and the prices $p_{s}^{i}$ are expressed in the same unit of account (for instance currency $i$ ), but the returns $R_{s j}^{i}$ are expressed in an another unit of account, here a physical good (for instance, good 1).

Note that our results do not depend of the unit of account (for instance, the currency or the physical good).

matically skew domestic consumption in favor of home-produced goods". This sentence supports the view that, if the LOP is not satisfied because of trade costs, a country can be tempted to turn inwards and, when taken to the limit, to experience autarky.

${ }^{7}$ Actually, in Hart (1974), in the first period, the agents trade assets and do not consume. 
Given the price vectors $q$ and $p_{s}^{i}$, the agent maximizes the utility function $h^{i}\left(x_{0}^{i}\right)+$ $u^{i}\left(x_{1}^{i}, \ldots, x_{S}^{i}\right)$ under a budget constraint in the first period:

$$
p_{0}^{i}\left(x_{0}^{i}-\omega_{0}^{i}\right)+q z^{i} \leq 0
$$

The list of budget constraints in the second period (state by state) depends on the case we are focusing on:

$$
\begin{array}{clc}
\text { case } 1 & : \quad p_{s}^{i}\left(x_{s}^{i}-\omega_{s}^{i}\right) \leq R_{s}^{i} z^{i} \\
\text { case } 2 & : & p_{s}^{i}\left(x_{s}^{i}-\omega_{s}^{i}\right) \leq p_{s 1}^{i} R_{s}^{i} z^{i}
\end{array}
$$

for every $s$. Notice that the return vector $R_{s}^{i}$ is in terms of good 1 in the second case.

\section{Definitions}

With our first definition, we introduce feasible sets for assets and goods.

Definition 1 (feasible sets). $\tilde{Z} \equiv\left\{\left(z^{1}, \ldots, z^{I}\right) \in \mathbb{R}^{I \times J}: \sum_{i} z^{i}=0\right\}$ is the feasible set for the assets of the countries.

$\tilde{X} \equiv\left\{\left(x_{0}^{1}, \ldots, x_{0}^{I},\left(x_{s}^{1}, \ldots, x_{s}^{I}\right)_{s}\right) \in \mathbb{R}_{+}^{I \times L \times(1+S)}: \sum_{i} x_{s l}^{i} \leq \sum_{i} \omega_{s l}^{i}\right.$ for any $l$ and $\left.s=0,1, \ldots, S\right\}$ is the feasible set for the consumption goods of the countries.

We observe that $\tilde{X}$ is compact and convex.

Our second definition concerns the notion of no-arbitrage price, a key concept in the financial literature.

Definition 2 (no-arbitrage price). A vector $q$ is a no-arbitrage price for the country $i$ if, for any $z$ such that $R_{s}^{i} z \geq 0$ in any state $s$ and $R_{t}^{i} z>0$ in some state $t$, we have $q z>0$.

$A$ vector $q$, which is a no-arbitrage vector for any country, is said to be a No-Arbitrage price (NA) for the whole economy.

From the Farkas' Lemma, $q$ is a no-arbitrage vector for a country $i$ if and only if there exist $S$ strictly positive numbers $\alpha_{s}^{i}$, such that $q=\sum_{s} \alpha_{s}^{i} R_{s}^{i}$. A vector $q$ is NA if and only if there are $I \times S$ strictly positive numbers $\alpha_{s}^{i}$, such that $q=\sum_{s} \alpha_{s}^{i} R_{s}^{i}$ for any $i$.

In our third definition, we provide a notion of parity for the real interest rate, commonly used in the theory of international finance.

Definition 3 (UIP). The Uncovered (real) Interest Rate Parity holds if, expressed in the same unit of account, $R_{s}^{i}=R_{s}^{j}$ for any $i$, any $j$ and $s$.

Finally, we introduce the no-arbitrage condition for goods prices.

Definition 4 (LOP). The Law of One Price is satisfied if, expressed in the same unit of account, the price is the same across the countries at any period, in any state, that is $p_{s l}^{j}=p_{s l}^{i}$ for any $j, i$ and $s \geq 0$. 


\section{Assumptions}

The main results of our model depend on the following assumptions.

A1 The utility functions $h^{i}, u^{i}$ are strictly increasing and strictly concave.

Endowments and returns are supposed to be strictly positive.

A2 $\omega_{s l}^{i}>0$ for any $i$ and $s \geq 0$.

A3 $R_{s j}^{i}>0$ for any $i, j$, and $s \geq 1$.

The assets are supposed to be non-redundant.

A4 rank of $R^{i}=J$, for any $i$.

A5 UIP holds.

A6 The unit of account is the same and each asset price $q_{j}$ in the first period is expressed in terms of this unit of account. The price vector $q$ is in the unit-ball for the sup-norm of $\mathbb{R}^{J}$.

A7 In periods 0 and 1, the price of each good is expressed in the same unit of account of the first period. For $s=0,1, \ldots, S$, in country $i$, the price vector is given by $p_{s}^{i}=\left(p_{s 1}^{i}, \ldots, p_{s L}^{i}\right)$. Prices are individualized on market $l$ if there exist $i, h$, and $s \geq 0$, such that $p_{s l}^{h} \neq p_{s l}^{i}$

A8 For any period, the $L O P$ holds in $M \leq L$ markets, say for $l=1, \ldots, M$. In other words, $p_{s l}^{i}=p_{\text {sl }}$ for any country $i$ and any $s \geq 0$ with $l \leq M$.

When $L>M$, there exist $L-M$ markets where the LOP does not hold. Namely, for $l=M+1, \ldots, L$, the prices $p_{s l}^{i}$ are individualized. A preliminary result is obtained under UIP.

Lemma 1. Under A5, an NA price exists.

Proof. Fix $S$ strictly positive numbers $\alpha_{s}$ and define $q=\sum_{s \geq 1} \alpha_{s} R_{s}$. Such a vector $q$ is a NA price.

Under these assumptions, using these definitions, we can prove the existence of equilibrium in our cases.

\section{Case 1: nominal returns}

In this case, the prices and the returns are expressed in the same unit of account; for instance, currency 1 or $i$. After writing the individual program, we derive the demands and, finally, we prove the existence of equilibrium.

\subsection{Demands}

Each (representative agent of a) country purchases consumption goods and assets in the first period and consumes in the second period.

Given the system of prices $\pi=\left(q,\left(p_{l}\right)_{l \leq M},\left(p_{l}^{i}\right)_{l>M}\right) \in \mathbb{R}^{J} \times \mathbb{R}^{M \times(S+1)} \times \mathbb{R}^{I \times(L-M) \times(S+1)}$ and the matrices of returns $R_{s}^{i}$ expressed in the unit of account, the agent $i$ computes her demands 
for assets and consumption goods by solving the following program:

$$
\begin{aligned}
& \max \left[h^{i}\left(x_{0}^{i}\right)+u^{i}\left(x_{1}^{i}, \ldots, x_{S}^{i}\right)\right] \\
& \text { subject to } \\
& \sum_{l \leq M} p_{0 l}^{i}\left(x_{0 l}^{i}-\omega_{0 l}^{i}\right)+\sum_{l>M} p_{0 l}^{i}\left(x_{0 l}^{i}-\omega_{0 l}^{i}\right)+q z^{i} \leq 0 \text { (first period) } \\
& \sum_{l \leq M} p_{s l}\left(x_{s l}^{i}-\omega_{s l}^{i}\right)+\sum_{l>M} p_{s l}^{i}\left(x_{s l}^{i}-\omega_{s l}^{i}\right) \leq R_{s} z^{i} \text { (second period) }
\end{aligned}
$$

for any $s \geq 1$.

In the budget constraints we take into account that the prices $p_{s l}$ with $s \geq 0$ of $M$ goods are common across the countries according to Assumption A8.

\subsection{Equilibrium}

In the following analysis, we introduce a new definition of equilibrium (equilibrium*) which is pertinent for a general economy where the LOP may not be satisfied. The notion of equilibrium* coincides with the standard one when the LOP holds.

\subsubsection{Equilibrium when the LOP holds}

In this case $M=L$. We recall the standard definition of equilibrium.

Definition 5 (equilibrium). An equilibrium is a list of prices and allocations $\left(\pi,\left(z^{i},\left(x_{s}^{i}\right)_{s \geq 0}\right)_{i}\right)^{*}$ such that

(1) $\pi^{*}=\left(q^{*}, p^{*}\right) \in \mathbb{R}_{++}^{J} \times \mathbb{R}^{L \times(S+1)}{ }_{++}$,

(2) $\left(z^{i},\left(x_{s}^{i}\right)_{s \geq 0}\right)^{*}$ is the optimal demand given the prices $\pi^{*}$ for any $i$,

(3) $\sum_{i} z^{i *}=0$

(4) $\sum_{i}\left(x_{s}^{i *}-\omega_{s}^{i}\right)=0$ for any $s \geq 0$.

We now give a second definition of equilibrium when the LOP holds.

Definition 6 (equilibrium*). An equilibrium* is a list of prices and allocations $\left(\pi,\left(z^{i},\left(x_{s}^{i}\right)_{s \geq 0}\right)_{i}\right)^{*}$ such that

(1) $\pi^{*}=\left(q^{*}, p^{*}\right) \in \mathbb{R}_{++}^{J} \times \mathbb{R}^{L \times(S+1)}{ }_{++}$,

(2) $\left(z^{i},\left(x_{s}^{i}\right)_{s>0}\right)^{*}$ is the optimal demand given the prices $\pi^{*}$ for any $i$,

(3) $\sum_{i} z^{i *}=0$

(4) for all $\pi^{1}=\left(p_{s l}\right) \in \mathbb{R}_{+}^{L \times(S+1)}$, we have

$$
\sum_{i} \sum_{l} p_{s l}\left(x_{s l}^{i *}-\omega_{s l}^{i}\right) \leq 0
$$

for any $s \geq 0$. 
Remark 1. The difference between the notion of equilibrium (corresponding to the standard definition) and that of equilibrium* lies in conditions (4) of Definitions 5 and 6. For an equilibrium, we require that any market clears while for an equilibrium * we require that, for any price system in $\mathbb{R}_{+}^{L \times S}$, there is no deficit of the total nominal trade balance.

We now prove that, under the LOP, the two definitions of equilibrium coincide.

Proposition 1. When the LOP holds, the notions of equilibrium and equilibrium* are equivalent.

Proof. See Appendix.

\subsubsection{Equilibrium when the LOP does not hold}

In this case, $M<L$ and the following generalization of the notion of equilibrium* (Definition 6) becomes pertinent.

Definition 7 (equilibrium*). An equilibrium ${ }^{*}$ is a list of prices and allocations $\left(\pi,\left(z^{i},\left(x_{s}^{i}\right)_{s \geq 0}\right)_{i}\right)^{*}$ such that

(1) $\pi^{*}=\left(q^{*},\left(p_{l}^{*}\right)_{l \leq M},\left(p_{l}^{i *}\right)_{i, l>M}\right) \in \mathbb{R}_{++}^{J} \times \mathbb{R}_{++}^{M \times(S+1)} \times \mathbb{R}_{++}^{(L-M) \times(S+1) \times I}$,

(2) $\left(z^{i},\left(x_{s}^{i}\right)_{s>0}\right)^{*}$ is the optimal demand given the prices $\pi^{*}$ for any $i$.

(3) $\sum_{i} z^{i *}=0$

(4) for all $\left(\pi^{1}, \pi^{2}\right)=\left(\left(p_{s l}\right)_{l \leq M},\left(p_{s l}^{i}\right)_{l>M}\right) \in \mathbb{R}_{+}^{M \times(S+1)} \times \mathbb{R}_{+}^{(L-M) \times(S+1) \times I}$, we have

$$
\sum_{i} \sum_{l \leq M} p_{s l}\left(x_{s l}^{i *}-\omega_{s l}^{i}\right)+\sum_{i} \sum_{l>M} p_{s l}^{i}\left(x_{s l}^{i *}-\omega_{s l}^{i}\right) \leq 0
$$

for any $s \geq 0$.

The economic interpretation of (5) is analogous to that of (4): there is no deficit of the total nominal trade balance when we use any price system in $\mathbb{R}_{+}^{M \times(S+1)} \times \mathbb{R}_{+}^{(L-M) \times(S+1) \times I}$.

Proposition 2. Let $\left(\pi,\left(z^{i},\left(x_{s}^{i}\right)_{s \geq 0}\right)_{i}\right)^{*}$ be an equilibrium*. Then, we have

(1) $\sum_{i} \sum_{l \leq M} p_{s l}^{*}\left(x_{s l}^{i *}-\omega_{s l}^{i}\right)+\sum_{i} \sum_{l>M} p_{s l}^{i *}\left(x_{s l}^{i *}-\omega_{s l}^{i}\right)=0$, for any $s \geq 0$,

(2) $\sum_{i}\left(x_{s l}^{i *}-\omega_{s l}^{i}\right)=0$ for any $i$ and $s \geq 0$, and for any $l \leq M$,

(3) $x_{s l}^{i *}=\omega_{s l}^{i}$ for any $i$ and $s \geq 0$, and for any $l>M$.

Therefore, in any equilibrium*, each country is autarkic for any market $l>M$.

Proof. See Appendix.

Proposition 3. A list $\left(\pi,\left(z^{i},\left(x_{s}^{i}\right)_{s \geq 0}\right)_{i}\right)^{*}$ is an equilibrium * if, and only if, it satisfies

(1) $\pi^{*} \in \mathbb{R}_{++}^{J} \times \mathbb{R}_{++}^{M \times(S+1)} \times \mathbb{R}_{++}^{(L-M) \times(S+1) \times I}$,

(2) $\left(z^{i},\left(x_{s}^{i}\right)_{s \geq 0}\right)^{*}$ is the optimal demand given the prices $\pi^{*}$ for any $i$,

(3) $\sum_{i} z^{i *}=0$,

and

(4) $\sum_{i}\left(x_{s l}^{i *}-\omega_{s l}^{i}\right)=0$ for any $i$ and $s \geq 0$, and for any $l \leq M$,

(5) $x_{s l}^{i *}=\omega_{s l}^{i}$ for any $i$ and $s \geq 0$, and for any $l>M$.

Proof. See Appendix. 


\subsection{Existence of equilibrium*}

We now prove the existence of equilibrium* when the LOP is not satisfied in our economy.

Let us introduce the restricted consumption and asset sets.

Definition 8 (restricted consumption set). Let $\tilde{X}^{i} \subset \mathbb{R}_{+}^{L \times(S+1)}$ be the projection of

$$
\tilde{X} \equiv\left\{\left(x_{s}^{i}\right) \in \mathbb{R}_{+}^{I \times L \times(S+1)} \text { such that } \sum_{i}\left(x_{s l}^{i}-\omega_{s l}^{i}\right) \leq 0 \text { for any } l \text { and } s \geq 0\right\}
$$

on the $i$-th component. Let $X$ be a closed ball of $\mathbb{R}^{L \times(S+1)}$ containing all the sets $\tilde{X}^{i}$ in its interior. We consider $X$ to be the consumption set.

We would also like to restrict the set of assets to a convex and compact set of $\mathbb{R}^{J}$. We define a restricted asset set and we prove its compactness as follows.

Let

$$
\begin{aligned}
& \Pi^{1} \equiv\left\{\pi^{1} \equiv\left(p_{s l}\right) \in \mathbb{R}^{M \times(S+1)}:\left|p_{s l}\right| \leq 1 \forall l \leq M \text { and } \forall s \geq 0\right\} \\
& \Pi^{2} \equiv\left\{\pi^{2} \equiv\left(p_{s l}^{i}\right) \in \mathbb{R}^{I \times(L-M) \times(S+1)}:\left|p_{s l}^{i}\right| \leq 1 \forall l>M \text { and } \forall i, \forall s \geq 0\right\}
\end{aligned}
$$

We denote by $\pi \equiv\left(q, \pi^{1}, \pi^{2}\right) \in \Pi$ a price vector and by $\Pi_{++}$the set of $\pi$ with strictly positive components.

Let $Z^{i}$ denote the set of portfolio $z^{i}$ satisfying for some $\left(\pi^{1}, \pi^{2}\right) \in \Pi^{1} \times \Pi^{2}$ and some $\left(x_{s}^{i}\right)_{s \geq 0} \in X$

$$
\sum_{l \leq M} p_{s l}\left(x_{s l}^{i}-\omega_{s l}^{i}\right)+\sum_{l>M} p_{s l}^{i}\left(x_{s l}^{i}-\omega_{s l}^{i}\right) \leq R_{s}^{i} z^{i}
$$

for any $s \geq 1$. Let $\hat{Z} \equiv\left\{\left(z^{1}, \ldots, z^{I}\right) \in \tilde{Z}: z^{i} \in Z^{i}, \forall i\right\}$ be a subset of $\tilde{Z}$.

Lemma 2. Under the Assumptions A3, A4 and A5 (UIP), the set $\hat{Z}$ is compact.

Proof. See Appendix.

Definition 9 (restricted asset set). Let $\hat{Z}^{i}$ be the projection of $\hat{Z}$ on the $i$-th component. Let $Z \subset \mathbb{R}^{J}$ be closed ball which contains all the sets $\hat{Z}^{i}$ in its interior. We consider $Z$ as the asset set.

Let us first consider an economy $\mathcal{E}_{1} \equiv\left(X, Z,\left(h^{i}, u^{i}, \omega^{i}, R\right)_{i}\right)$ and prove that an equilibrium always exists in this economy. Moreover, it is partially autarkic with $x_{s l}^{i *}=\omega_{s l}^{i}$ for any $l>M$ and any $s \geq 0$.

In a second stage, we shall prove that this equilibrium of economy $\mathcal{E}_{1}$ is actually an equilibrium of the initial unbounded economy.

In order to provide a simple proof, we introduce the Inada conditions on the utility functions. Without these conditions, a more general proof holds but we should introduce multipliers associated with nonnegative consumption. 
Theorem 1 (existence of equilibrium*). Let Assumptions A1-A8 hold and the utility functions

$$
h^{i}\left(x_{0}^{i}\right), u^{i}\left(x_{1}^{i}, \ldots, x_{S}^{i}\right)
$$

with $x_{s}^{i} \in \mathbb{R}_{+}^{L}$ for $s \geq 0$, be strictly concave, strictly increasing and differentiable, and satisfy

$$
\frac{\partial h^{i}}{\partial x_{0 l}^{i}}\left(x_{0}^{i}\right)=+\infty \text { if } x_{0 l}^{i}=0, \text { and } \frac{\partial u^{i}}{\partial x_{s l}^{i}}\left(x_{1}^{i}, \ldots x_{S}^{i}\right)=+\infty \text { if } x_{s l}^{i}=0
$$

for any $l$ and $s \geq 1$.

Then, there exists an equilibrium* $\left(\pi,\left(z^{i},\left(x_{s}^{i}\right)_{s \geq 0}\right)_{i}\right)^{*}$. Hence,

(1) $\sum_{i}\left(x_{s l}^{i *}-\omega_{s l}^{i}\right)=0$ for any $s \geq 0$ and any $l \leq M$,

(2) $x_{s l}^{i *}=\omega_{s l}^{i}$ for any $i$ and $s \geq 0$, and any $l>M$.

Proof. See Appendix. ${ }^{8}$

Remark 2. If $M=0$, the LOP fails in any market and the equilibrium in Theorem 1 corresponds to an autarkic economy with $z^{i *}=0$ and $x^{i *}=\omega^{i}$ for any $i$.

If $M=L$, we get the same result as in Florenzano (1999).

\section{Case 2: real returns}

In this case, the returns are expressed in terms of the same unit of account, here a physical good; for instance the good 1. Note that using this good or an another good does not impact our results. After writing the individual program, we derive the demands and, finally, prove the existence of equilibrium.

\subsection{Demands}

Each (representative agent of a) country purchases consumption goods and assets in the first period and consumes in the second period.

Given the system of prices $\pi=\left(q,\left(p_{l}\right)_{l \leq M},\left(p_{l}^{i}\right)_{l>M}\right) \in \mathbb{R}^{J} \times \mathbb{R}^{M \times(S+1)} \times \mathbb{R}^{I \times(L-M) \times(S+1)}$ and the matrixes of physical returns $R_{s}^{i}$, the agent $i$ computes her demands for assets and consumption goods solving the following program:

$$
\begin{aligned}
& \max \left[h^{i}\left(x_{0}^{i}\right)+u^{i}\left(x_{1}^{i}, \ldots, x_{S}^{i}\right)\right] \\
& \text { subject to } \\
& \sum_{l \leq M} p_{0 l}^{i}\left(x_{0 l}^{i}-\omega_{0 l}^{i}\right)+\sum_{l>M} p_{0 l}^{i}\left(x_{0 l}^{i}-\omega_{0 l}^{i}\right)+q z^{i} \leq 0 \text { (first period) } \\
& \sum_{l \leq M} p_{s l}\left(x_{s l}^{i}-\omega_{s l}^{i}\right)+\sum_{l>M} p_{s l}^{i}\left(x_{s l}^{i}-\omega_{s l}^{i}\right) \leq p_{s 1} R_{s}^{i} z^{i} \text { (second period) }
\end{aligned}
$$

for any $s \geq 1$.

\footnotetext{
${ }^{8}$ For the proof, we use the Cass trick (Cass, 1984, Florenzano, 1999) which shows that, for any list of $S$ positive real numbers, $\left(\lambda_{1}, \ldots, \lambda_{S}\right)$, the assets price is $q^{*}=\sum_{s=1}^{S} \lambda_{s} R_{s}$, where $\left(R_{s}\right)_{s}$ is the returns matrix.
} 


\subsection{Equilibrium}

Let us focus directly on the general case, that is on the possibility of LOP failure.

Definition 10 (equilibrium*). An equilibrium* is a list of prices and allocations $\left(\pi,\left(z^{i},\left(x_{s}^{i}\right)_{s \geq 0}\right)_{i}\right)^{*}$ such that

(1) $\pi^{*} \in \mathbb{R}_{++}^{J} \times \mathbb{R}_{++}^{M \times(S+1)} \times \mathbb{R}_{++}^{(L-M) \times(S+1) \times I}$,

(2) $\left(z^{i},\left(x_{s}^{i}\right)_{s \geq 0}\right)^{*}$ is the optimal demand given the prices $\pi^{*}$ for any $i$,

(3) $\sum_{i} z^{i *}=0$

(4) for all $\left(\pi^{1}, \pi^{2}\right)=\left(\left(p_{s l}\right)_{l \leq M},\left(p_{s l}^{i}\right)_{l>M}\right) \in \mathbb{R}_{+}^{M \times(S+1)} \times \mathbb{R}_{+}^{(L-M) \times(S+1) \times I}$, we have

$$
\sum_{i} \sum_{l \leq M} p_{s l}\left(x_{s l}^{i *}-\omega_{s l}^{i}\right)+\sum_{i} \sum_{l>M} p_{s l}^{i}\left(x_{s l}^{i *}-\omega_{s l}^{i}\right) \leq 0
$$

for any $s \geq 0$.

As above, one can show that, in any equilibrium*, each country is autarkic for any market $l>M$.

Proposition 4. A list $\left(\pi,\left(z^{i},\left(x_{s}^{i}\right)_{s \geq 0}\right)_{i}\right)^{*}$ is an equilibrium* if, and only if, it satisfies

(1) $\pi^{*} \in \mathbb{R}_{++}^{J} \times \mathbb{R}_{++}^{M \times(S+1)} \times \mathbb{R}_{++}^{(L-M) \times(S+1) \times I}$,

(2) $\left(z^{i},\left(x_{s}^{i}\right)_{s>0}\right)^{*}$ is the optimal demand given the prices $\pi^{*}$ for any $i$,

(3) $\sum_{i} z^{i *}=0$

and

(4) $\sum_{i}\left(x_{s l}^{i *}-\omega_{s l}^{i}\right)=0$ for any $i$ and $s \geq 0$, and for any $l \leq M$,

(5) $x_{s l}^{i *}=\omega_{s l}^{i}$ for any $i$ and $s \geq 0$, and for any $l>M$.

The proof is the same as that of Proposition 3.

\subsection{Existence of equilibrium*}

We will make use of the consumption sets $X$ in Definition 8. For the financial assets, we impose, for any $i, Z_{b}^{i}=\left\{z \in \mathbb{R}^{j}: z_{j} \geq-b, \forall j\right\}$ where $b>0$ is given. Let $\hat{Z}_{b} \equiv$ $\left\{\left(z^{1}, \ldots, z^{I}\right) \in \tilde{Z}: z^{i} \in Z_{b}^{i}, \forall i\right\}$ be a subset of $\tilde{Z}$ (recall that $\tilde{Z} \equiv\left\{\left(z^{1}, \ldots, z^{I}\right) \in \mathbb{R}^{I \times J}: \sum_{i} z^{i}=0\right\}$ ).

It is obvious that $\hat{Z}_{b}$ is convex, compact.

Definition 11 (restricted asset set). Let $\hat{Z}_{b}^{i}$ be the projection of $\hat{Z}_{b}$ on the $i$-th component. Let $Z_{b} \subset \mathbb{R}^{J}$ be closed ball which contains all the sets $\hat{Z}_{b}^{i}$ in its interior. We consider $Z_{b}$ as the asset set. Let us first consider an economy $\mathcal{E}_{2, b} \equiv\left(X, Z_{b},\left(h^{i}, u^{i}, \omega^{i}, R\right)_{i}\right)$ and prove that an equilibrium* always exists in this economy.

Theorem 2 (existence of equilibrium*). Let Assumptions A1-A9 hold and the utility functions

$$
h^{i}\left(x_{0}^{i}\right), u^{i}\left(x_{1}^{i}, \ldots, x_{S}^{i}\right)
$$


with $x_{s}^{i} \in \mathbb{R}_{+}^{L}$ for any $s \geq 0$, be strictly concave, strictly increasing and differentiable, and satisfy

$$
\frac{\partial h^{i}}{\partial x_{0 l}^{i}}\left(x_{0}^{i}\right)=+\infty \text { if } x_{0 l}^{i}=0 ; \frac{\partial u^{i}}{\partial x_{s l}^{i}}\left(x_{1}^{i}, \ldots x_{S}^{i}\right)=+\infty \text { if } x_{s l}^{i}=0
$$

for any $l$ and $s \geq 1$.

Then, there exists an equilibrium $*\left(\pi(b),\left(z^{i}(b),\left(x_{s}^{i}(b)\right)_{s \geq 0}\right)_{i}\right)^{*}$. Hence

(1) $\sum_{i}\left(x_{s l}^{i *}(b)-\omega_{s l}^{i}\right)=0$ for any $s \geq 0$ and any $l \leq M$,

(2) $x_{s l}^{i *}(b)=\omega_{s l}^{i}$ for any $i$ and $s \geq 0$, and any $l>M$.

Proof. See Appendix.

At the second stage, we show that the equilibrium* $\left(\pi(b),\left(z^{i}(b),\left(x_{s}^{i}(b)\right)_{s \geq 0}\right)_{i}\right)^{*}$ converges to $\left(\bar{\pi},\left(\bar{z}^{i},\left(\bar{x}_{s}^{i}\right)_{s \geq 0}\right)_{i}\right)$, when $b \rightarrow+\infty$, which satisfies

- $\bar{\pi}>>0$

- $\left(\bar{x}_{s}^{i}\right) \in X$

- $\bar{z}^{i} \in \mathbb{R}^{J}$

- $\sum_{i}\left(\bar{x}_{s l}^{i}-\omega_{s l}^{i}\right)=0$ for any $s \geq 0$ and any $l \leq M$,

- $\bar{x}_{s l}^{i}=\omega_{s l}^{i}$ for any $i$ and $s \geq 0$, and any $l>M$.

And finally, we prove that $\left(\bar{\pi},\left(\bar{z}^{i},\left(\bar{x}_{s}^{i}\right)_{s \geq 0}\right)_{i}\right)$ is an equilibrium for the initial unbounded economy.

Remark 3. (1) Case 2 corresponds to a particular model with real assets where the returns are delivered in a single good. An equilibrium of this model is identical to an equilibrium of a model with the following program:

$$
\begin{aligned}
& \max \left[h^{i}\left(x_{0}^{i}\right)+u^{i}\left(x_{1}^{i}, \ldots, x_{S}^{i}\right)\right] \\
& \text { subject to } \\
& \sum_{l \leq M} p_{0 l}^{i}\left(x_{0 l}^{i}-\omega_{0 l}^{i}\right)+\sum_{l>M} p_{0 l}^{i}\left(x_{0 l}^{i}-\omega_{0 l}^{i}\right)+q z^{i} \leq 0 \text { (first period) } \\
& x_{s 1}^{i}-\omega_{s 1}^{i}+\sum_{2 \leq l \leq M} p_{s l}\left(x_{s l}^{i}-\omega_{s l}^{i}\right)+\sum_{l>M} p_{s l}^{i}\left(x_{s l}^{i}-\omega_{s l}^{i}\right) \leq R_{s}^{i} z^{i} \text { (second period) }
\end{aligned}
$$

for any $s \geq 1$. Indeed, we can divide both the sides in the second-period constraints by $p_{s 1}^{*}$. The new prices will be given by $\tilde{p}_{s}^{*} \equiv p_{s}^{*} / p_{s 1}^{*}$ The model of Case 2 generalizes Bosi et al. (2016).

(2) In this paper we have real returns in term of consumption good 1. And we have many consumption goods. In Dana and Jeanblanc-Picqué (2003), for the real returns there is one consumption good 
Remark 4. (a) Observe at any equilibrium* we also have, for any $s, \sum_{i}\left(x_{s}^{i *}-\omega_{s}^{i}\right)=0$ as in the case of $L O P$.

(b) Actually, since the prices are individualized for goods $l>M$, we have, following Debreu (1959), for each country, $L-M$ different markets. Each country is interested only by its own markets. That explains why they are autarkic for these goods markets

(c) We can explain the autarky by a no-arbitrage condition as follows.

Suppose for good $l$, at state $s$, LOP does not work in countries $i$ and $j$. There are individualized prices $p_{s l}^{i}, p_{s l}^{j}$.

However we assume that agent of country $i$ can buy good $l$ in country $j$ and vice-versa.

Agent of country $i$ buys a quantity $c_{s l}$ with price $p_{\text {sl }}^{j}$ and resells this quantity in its domestic market with price $p_{s l}^{i}$ (we suppose there is no transaction cost, no transportation cost). Agent of country $i$ may consume more good $l$ and will be better off. There is an opportunity of arbitrage for agent of country $i$ if $c_{s l}>0$ and $p_{s l}^{j} c_{s l}-p_{s l}^{i} c_{s l}<0$. In this case, agent of country $i$ will never stop buying good $l$ in country $j$.

Symmetrically, there is an opportunity of arbitrage for agent of country $j$ if $c_{s l}>0$ and $p_{s l}^{i} c_{s l}-p_{s l}^{j} c_{s l}<0$.

To have no opportunity of arbitrage in both countries, we impose that

$$
\forall c_{s l} \geq 0, p_{s l}^{j} c_{s l}-p_{s l}^{i} c_{s l} \geq 0 \text { and } p_{s l}^{i} c_{s l}-p_{s l}^{j} c_{s l} \geq 0 \Leftrightarrow p_{s l}^{j} c_{s l}-p_{s l}^{i} c_{s l}=0
$$

As $p_{s l}^{j} \neq p_{s l}^{i}$ we must have $c_{s l}=0$. Both countries must be in autarky.

Remark 5 (exchange rate, interest rates policies under the LOP and UIP). We focus on the exchange rates to interpret these findings. Let us consider, for simplicity, the case of nominal returns and two currencies $i$ and $j$. We denote by $\tau_{s}^{i}$ the exchange rate of currency $i$ relative to currency $j$ : one unit of currency $i$ equals $\tau_{s}^{i}$ units of currency $j$. Let $\tilde{p}_{s}^{i *}$ and $\tilde{R}_{s}^{i}$ be the price and return in terms of currency $i$.

For prices, the LOP requires $\tau_{s}^{i} \tilde{p}_{s}^{i *}=p_{s}^{j *}$. Thus, the international equilibrium prices fix the values of prices in currency $j$. The same comment applies for individual prices.

For returns, UIP requires $\tau_{s}^{i} \tilde{R}_{s}^{i}=R_{s}^{j}$. Country $i$ must impose, up to the exchange rate, the same returns as country $j$. Suppose asset $j$ is a riskless asset, i.e. $R_{s}^{j}=R^{j}$ for all $s$. We define the interest rate $r$ by $1+r^{j}=R^{j}$. In particular, after adjustement for exchange rates, the interest rate must be the same for any country.

\section{Conclusion}

We have plausibly considered fully globalized financial markets to be markets with the same asset prices (adjusted for exchange rates) across all countries. These globalized financial markets result in UIP, a no-arbitrage condition entailing the same returns (adjusted for exchange rates) in all countries.

In contrast, as observation of the real world suggests, trade in goods seems to be less globalized: some markets are indeed subject to trade barriers. In our model, globalized markets are those in which the LOP holds. At equilibrium, these markets experience a balance of trade. For other markets, in which tariff barriers impede trade, we have introduced the notion of equilibrium*. 
An equilibrium* exhibits two features:

(1) the total nominal value of trade is balanced;

(2) for any non-negative individualized system of prices, the total nominal value of demands does not exceed the total value of supply.

This equilibrium has a robust economic property: markets under trade barriers are autarkic.

The explanation might be as follows

(a) Actually, since the prices are individualized for goods $l>M$, we have, following Debreu (1959), for each country, $L-M$ different markets . Each country is interested only by its own markets. That explains why they are autarkic for these goods markets (Remark 4 (b).)

(b) We introduce a notion of no-arbitrage which implies either we have LOP, or autarky if no LOP (See Remark 4 (c)).

\section{Appendix}

For the proofs of existence of equilibrium we will use the set of prices $\Pi \equiv Q \times \Pi^{1} \times \Pi^{2}$ for both the periods with

$$
\begin{aligned}
Q & \equiv\left\{q \in \mathbb{R}^{J}:\left|q_{j}\right| \leq 1 \forall j\right\} \\
\Pi^{1} & \equiv\left\{\pi^{1} \equiv\left(p_{s l}\right) \in \mathbb{R}^{M \times(S+1)}:\left|p_{s l}\right| \leq 1 \forall l \leq M \text { and } \forall s \geq 0\right\} \\
\Pi^{2} & \equiv\left\{\pi^{2} \equiv\left(p_{s l}^{i}\right) \in \mathbb{R}^{I \times(L-M) \times(S+1)}:\left|p_{s l}^{i}\right| \leq 1 \forall l>M \text { and } \forall i, \forall s \geq 0\right\}
\end{aligned}
$$

We denote by $\pi \equiv\left(q, \pi^{1}, \pi^{2}\right) \in \Pi$ a price vector and by $\Pi_{++}$the set of $\pi$ with strictly positive components.

Proof of Proposition 1

(1) Consider the equilibrium allocations. Condition (4) of Definition 5 implies for any $s \geq 0$

$$
\sum_{i} \sum_{l} p_{s l}\left(x_{s l}^{i *}-\omega_{s l}^{i}\right)=0
$$

for all $\pi \in \Pi_{+}^{1}$.

(2) Let $\left(\left(x_{s}^{i}\right)_{s}\right)_{i}^{*}$ be an equilibrium* allocation. Suppose that, for some pair $(s, l)$, we have $\sum_{i} x_{s l}^{i *}>\sum_{i} \omega_{s l}^{i}$. In this case, take $p_{s l}=1$ and $p_{\sigma \lambda}=0$ for any pair $(\sigma, \lambda) \neq(s, l)$. We have $\sum_{i} \sum_{l} p_{s l}\left(x_{s l}^{i *}-\omega_{s l}^{i}\right)>0$, which contradicts the definition of equilibrium*. Hence, $\sum_{i} x_{s l}^{i *} \leq$ $\sum_{i} \omega_{s l}^{i}$ for any pair $(s, l)$. Now, suppose that, for some pair $(s, l)$, we have $\sum_{i} x_{s l}^{i *}<\sum_{i} \omega_{s l}^{i}$. Since $\pi^{*} \in \Pi_{++}$, we have $\sum_{i} \sum_{l} p_{s l}^{*}\left(x_{s l}^{i *}-\omega_{s l}^{i}\right)<0$. This contradicts the fact that, in an equilibrium*, all the budget constraints are binding and, therefore, $\sum_{i} \sum_{l} p_{s l}^{*}\left(x_{s l}^{i *}-\omega_{s l}^{i}\right)=0$.

Proof of Proposition 2

(1) At equilibrium, since the utility functions are strictly increasing, we have, for all $i$,

$$
\begin{aligned}
& \sum_{l \leq M} p_{0 l}^{i}\left(x_{0 l}^{i *}-\omega_{0 l}^{i}\right)+\sum_{l>M} p_{0 l}^{i *}\left(x_{0 l}^{i *}-\omega_{0 l}^{i}\right)+q^{*} z^{i *}=0 \\
& \sum_{l \leq M} p_{s l}^{*}\left(x_{s l}^{i *}-\omega_{s l}^{i}\right)+\sum_{l>M} p_{s l}^{i *}\left(x_{s l}^{i *}-\omega_{s l}^{i}\right)=R_{s} z^{i *}
\end{aligned}
$$


Summing over $i$, we get the result.

(2) Consider (5). Take $p_{s l}^{i}=0$, for any $i$ and $s$, and any $l>M$ to obtain $\sum_{i} \sum_{l \leq M} p_{s l}\left(x_{s l}^{i *}-\omega_{s l}^{i}\right) \leq$ 0 for all $\pi^{1} \in \Pi_{+}^{1}$. Following the proof of point 2 in Proposition 1, we see that, if $\sum_{i} x_{s l}^{i *}>$ $\sum_{i} \omega_{s l}^{i}$ for some pair $(s, l)$ with $l \leq M$, we can choose $\pi^{1} \in \Pi_{+}^{1}$ such that $\sum_{i} \sum_{l \leq M} p_{s l}\left(x_{s l}^{i *}-\omega_{s l}^{i}\right)>$ 0 , that contradicts the definition of equilibrium*. Now, suppose that, for some pair $(s, l)$, we have $\sum_{i} x_{s l}^{i *}<\sum_{i} \omega_{s l}^{i}$ for some pair $(s, l)$ with $l \leq M$. Considering $\pi^{1 *} \in \Pi_{++}^{1}$, we obtain $\sum_{i} \sum_{l} p_{s l}^{*}\left(x_{s l}^{i *}-\omega_{s l}^{i}\right)<0$. This contradicts the fact that, in an equilibrium*, all the budget constraints are binding and, therefore, $\sum_{i} \sum_{l} p_{s l}^{*}\left(x_{s l}^{i *}-\omega_{s l}^{i}\right)=0$.

(3) Now, take $p_{s l}=0$ for any pair $(s, l)$ with $l \leq M$. Assume that, for some triplet $(h, t, m)$ with $m>M$, we have $x_{t m}^{h *}-\omega_{t m}^{h}>0$. In this case, take $p_{t m}^{h}=1$ and $p_{s l}^{i}=$ 0 , for any pair $(i, s, l) \neq(h, t, m)$ with $l>M$. We obtain $\sum_{i} \sum_{l \leq M} p_{s l}\left(x_{s l}^{i *}-\omega_{s l}^{i}\right)+$ $\sum_{i} \sum_{l>M} p_{s l}^{i}\left(x_{s l}^{i *}-\omega_{s l}^{i}\right)>0$ : a contradiction. Hence, for any triplet $(i, s, l)$, we have $x_{s l}^{i *}-$ $\omega_{s l}^{i} \leq 0$.

If, for some triplet $(h, t, m)$ with $m>M$, we have $x_{t m}^{h *}-\omega_{t m}^{h}<0$, since $\pi^{h *} \in \Pi_{++}^{2}$ we get $\sum_{i} \sum_{l<M} p_{s l}^{*}\left(x_{s l}^{i *}-\omega_{s l}^{i}\right)+\sum_{i} \sum_{l>M} p_{s l}^{i *}\left(x_{s l}^{i *}-\omega_{s l}^{i}\right)<0$ in contradiction with the fact that, at equilibrium*, all the budget constraints are binding and, then, $\sum_{i} \sum_{l \leq M} p_{s l}^{*}\left(x_{s l}^{i *}-\omega_{s l}^{i}\right)+$ $\sum_{i} \sum_{l>M} p_{s l}^{i *}\left(x_{s l}^{i *}-\omega_{s l}^{i}\right)=0$. Hence, $x_{s l}^{i *}-\omega_{s l}^{i}=0$ for all the triplets $(i, s, l)$.

\section{Proof of Proposition 3}

Apply Proposition 2 and consider the fact that any list $\left(\pi,\left(z^{i},\left(x_{s}^{i}\right)_{s}\right)_{i}\right)^{*}$ which satisfies the conditions of Proposition 3 also satisfies the conditions of an equilibrium*.

\section{Proof of Lemma 2}

Clearly, $\hat{Z}$ is closed. It remains to prove that it is bounded. Let us assume the contrary. Then, there exists a sequence $\left\{\left(z^{1 n}, \ldots, z^{I n}\right)\right\}_{n} \subset \hat{Z}$ with $\delta_{n} \equiv \sum_{i}\left\|z^{i n}\right\| \rightarrow+\infty$ as $n \rightarrow+\infty$. It is possible to show that $\lim _{n \rightarrow+\infty} z^{i n} / \delta_{n}=\zeta^{i}$ for any $i$ with $\left(\zeta^{1}, \ldots, \zeta^{I}\right) \neq 0$ and $\sum_{i} \zeta^{i}=0$.

We have $\sum_{l \leq M} p_{s l}^{n}\left(x_{s l}^{i n}-\omega_{s l}^{i}\right)+\sum_{l>M} p_{s l}^{i n}\left(x_{s l}^{i n}-\omega_{s l}^{i}\right) \leq R_{s} z^{i n}$ for any $n$ and $s$. Dividing both the members of this inequality by $\delta_{n}$ and letting $n \rightarrow+\infty$, we find $0 \leq R_{s} \zeta^{i}$ for any $s$. From Lemma 1, there exists a NA price. Let us express the NA price vector as a linear combination: $q=\sum_{s} \alpha_{s} R_{s}$ with $\alpha_{s}>0$ for any $s$. We obtain $q \zeta^{i} \geq 0$ for any $i$. Since $\sum_{i} \zeta^{i}=0$, we obtain $q \zeta^{i}=0$ for any $i$.

Let $i$ satisfy $\zeta^{i} \neq 0$. We claim that there exists $t \in\{1, \ldots, S\}$ such that that $R_{t} \zeta^{i}>0$. If not, $R_{s} \zeta^{i}=0$ for any $s$. Since the matrix $R_{s}$ is of rank $J$, we have $\zeta^{i}=0$ yielding a contradiction. Since $q$ is NA, we have $q \zeta^{i}>0$ : a contradiction.

Hence $\hat{Z}$ is compact.

\section{Proof of Theorem 1}

Let $\pi \in \Pi$. Consider the budget sets $B^{i}(\pi)$ associated with the price system $\pi$ :

$$
B^{i}(\pi) \equiv\left\{\begin{array}{c}
\left(x^{i}, z^{i}\right) \in X \times Z: \\
\sum_{l \leq M} p_{0 l}\left(x_{0 l}^{i}-\omega_{0 l}^{i}\right)+\sum_{l>M} p_{0 l}^{i}\left(x_{0 l}^{i}-\omega_{0 l}^{i}\right)+q z^{i} \leq 0 \\
\sum_{l \leq M} p_{s l}\left(x_{s l}^{i}-\omega_{s l}^{i}\right)+\sum_{l>M} p_{s l}^{i}\left(x_{s l}^{i}-\omega_{s l}^{i}\right) \leq R_{s} z^{i} \forall s \geq 1
\end{array}\right\}
$$

The proof is articulated in three steps.

Step 1

First, we consider a two-period economy $\mathcal{F}_{1}$ with $I$ countries, $J$ assets and $M$ consumption goods. We define for any $s \geq 0$

$$
y_{s}^{i} \equiv\left(y_{s 1}^{i}, \ldots, y_{s M}^{i}\right) \text { and } \tilde{\omega}_{s}^{i} \equiv\left(\omega_{s(M+1)}^{i}, \ldots, \omega_{s L}^{i}\right)
$$


and the following utility functions

$$
k^{i}\left(y_{0}^{i}\right) \equiv h^{i}\left(\left(y_{0}^{i}, \tilde{\omega}_{0}^{i}\right)\right) \text { and } v^{i}\left(y_{1}^{i}, \ldots, y_{S}^{i}\right) \equiv u^{i}\left(\left(y_{1}^{i}, \tilde{\omega}_{1}^{i}\right), \ldots,\left(y_{S}^{i}, \tilde{\omega}_{S}^{i}\right)\right)
$$

for any $i$.

Let $\tilde{Y}^{i} \subset \mathbb{R}_{+}^{M \times(S+1)}$ be the projection of

$$
\tilde{Y} \equiv\left\{\left(x_{s}^{i}\right) \in \mathbb{R}_{+}^{I \times M \times(S+1)}: \sum_{i}\left(x_{s l}^{i}-\omega_{s l}^{i}\right) \leq 0 \text { for any } \forall l \leq M \text { and } \forall s \geq 0\right\}
$$

on the $i$-th component. Let $Y$ be a closed ball of $\mathbb{R}^{M \times(S+1)}$ containing all the $\tilde{Y}^{i}$ in its interior. We consider $Y$ as the consumption set. For the economy $\mathcal{F}_{1}$, the set of prices for both periods is given by $\tilde{\Pi} \equiv Q \times \Pi^{1}$ with

$$
\begin{aligned}
Q & \equiv\left\{q \in \mathbb{R}^{J}:\left|q_{j}\right| \leq 1 \forall j\right\} \\
\Pi^{1} & \equiv\left\{\pi^{1} \in \mathbb{R}^{M \times(S+1)}:\left|p_{s l}\right| \leq 1 \forall l \leq M \text { and } \forall s \geq 0\right\}
\end{aligned}
$$

We denote the prices vector by $\tilde{\pi} \equiv\left(q, \pi^{1}\right) \in \tilde{\Pi}$ and the set of $\tilde{\pi}$ with strictly positive components by $\tilde{\Pi}_{++}$.

Each representative agent of a country purchases consumption goods and assets in the first period and consumes in the second period. Given the system of prices $\tilde{\pi} \in \tilde{\Pi}$, an agent $i$ computes her optimal demands for assets and consumption goods according to the following program:

$$
\begin{aligned}
& \max k^{i}\left(y_{0}^{i}\right)+v^{i}\left(y_{1}^{i}, \ldots, y_{S}^{i}\right) \\
& \text { subject to } \\
& \sum_{l \leq M} p_{0 l}\left(y_{0 l}^{i}-\omega_{0 l}^{i}\right)+q z^{i} \leq 0 \text { (first period) } \\
& \sum_{l \leq M} p_{s l}\left(y_{s l}^{i}-\omega_{s l}^{i}\right) \leq R_{s} z^{i} \text { (second period) }
\end{aligned}
$$

for any $s \geq 1$.

An equilibrium of $\mathcal{E}_{1}$ is a list $\left(\tilde{\pi},\left(z^{i},\left(y_{s}^{i}\right)_{s \geq 0}\right)_{i}\right)^{*}$ such that

(1) $\tilde{\pi}^{*} \in \tilde{\Pi}_{++}$,

(2) $\sum_{i} z^{i *}=0$

(3) $\sum_{i}\left(y_{s l}^{i *}-\omega_{s l}^{i}\right)=0$ for any $l \leq M$ and for any $s \geq 0$,

(4) $\left(z^{i},\left(y_{s}^{i}\right)_{s \geq 0}\right)^{*}$ is the optimal demand given the prices $\tilde{\pi}^{*}$ for any $i$.

Under our assumptions, from Florenzano (1999), there exists an equilibrium $\left(\tilde{\pi},\left(z^{i},\left(y_{s}^{i}\right)_{s \geq 0}\right)_{i}\right)^{*} \cdot{ }^{9}$

Step 2

The equilibrium $\left(\tilde{\pi},\left(z^{i},\left(y_{s}^{i}\right)_{s \geq 0}\right)_{i}\right)^{*}$ satisfies the following first-order conditions:

\footnotetext{
${ }^{9}$ For the proof, we use the Cass trick (Cass, 1984, Florenzano, 1999) which shows that, for any list of $S$ positive real numbers, $\left(\lambda_{1}, \ldots, \lambda_{S}\right)$, the assets price is $q^{*}=\sum_{s=1}^{S} \lambda_{s} R_{s}$, where $\left(R_{s}\right)_{s}$ is the returns matrix.
} 
(1) for any $i, \mu^{i} q^{*}=\sum_{s} \lambda_{s}^{i} R_{s}$, where $\mu^{i}$ is the nonnegative multiplier of the first-period budget constraint and the $\lambda_{s}^{i}$ are the nonnegative multipliers of the second-period budget constraints;

(2) for $l \leq M$,

$$
\begin{aligned}
\frac{\partial k^{i}}{\partial y_{0 l}^{i}}\left(y_{01}^{i *}, \ldots, y_{0 M}^{i *}\right) & =\frac{\partial h^{i}}{\partial x_{0 l}^{i}}\left(\left(y_{0}^{i *}, \tilde{\omega}_{0}^{i}\right)\right)=\mu^{i} \tilde{p}_{0 l}^{*} \\
\frac{\partial v^{i}}{\partial y_{s l}^{i}}\left(y_{s 1}^{i *}, \ldots, y_{s M}^{i *}\right) & =\frac{\partial u^{i}}{\partial x_{s l}^{i}}\left(\left(y_{1}^{i *}, \tilde{\omega}_{1}^{i}\right), \ldots,\left(y_{S}^{i *}, \tilde{\omega}_{S}^{i}\right)\right)=\lambda_{s}^{i} \tilde{p}_{s l}^{*} \forall s \geq 1
\end{aligned}
$$

(3) $\sum_{l \leq M} \tilde{p}_{0 l}^{*}\left(x_{0 l}^{i *}-\omega_{0 l}^{i}\right)+q^{*} z^{i *}=0$ and $\sum_{l \leq M} \tilde{p}_{s l}^{*}\left(x_{s l}^{i *}-\omega_{s l}^{i}\right)=R_{s} z^{i *}$ for all $s \geq 1$. Define for $l>M$

$$
\begin{aligned}
& \tilde{p}_{0 l}^{i *}=\frac{1}{\mu^{i}} \frac{\partial h^{i}}{\partial x_{0 l}^{i}}\left(\left(y_{0}^{i *}, \tilde{\omega}_{0}^{i}\right)\right) \\
& \tilde{p}_{s l}^{i *}=\frac{1}{\lambda_{s}^{i}} \frac{\partial u^{i}}{\partial x_{s l}^{i}}\left(\left(y_{1}^{i *}, \tilde{\omega}_{1}^{i}\right), \ldots,\left(y_{S}^{i *}, \tilde{\omega}_{S}^{i}\right)\right)
\end{aligned}
$$

We claim that the list $\left(\tilde{\pi},\left(z^{i},\left(x_{s}^{i}\right)_{s}\right)_{i}\right)^{*}$, where

(1) $x_{s l}^{i *}=y_{s l}^{i *}$ for any $l \leq M$,

(2) $x_{s l}^{i *}=\omega_{s l}^{i}$ for any $l>M$,

(3) for any $l>M, \tilde{p}_{0 l}^{i *}$ is given by (6) and $\tilde{p}_{s l}^{i *}$ is given by (7),

(4) the prices $q^{*}, \tilde{p}_{0 l}^{*}$ and $\tilde{p}_{s l}^{*}$ for any $l \leq M$ are those of Step 1 ,

(5) the portfolio $z^{i *}$ is that of Step 1 ,

is an equilibrium of the initial economy $\mathcal{E}_{1}$.

Indeed, let $\left(\left(x_{s l}^{i}\right), z^{i}\right)$ with $l=1, \ldots, L$ satisfy

$$
\begin{aligned}
\sum_{l \leq M} \tilde{p}_{0 l}^{*}\left(x_{0 l}^{i}-\omega_{0 l}^{i}\right)+\sum_{l>M} \tilde{p}_{0 l}^{i *}\left(x_{0 l}^{i}-\omega_{0 l}^{i}\right)+q^{*} z^{i} & \leq 0 \\
\sum_{l \leq M} \tilde{p}_{s l}^{*}\left(x_{s l}^{i}-\omega_{s l}^{i}\right)+\sum_{l>M} \tilde{p}_{s l}^{i *}\left(x_{s l}^{i}-\omega_{s l}^{i}\right) & \leq R_{s} z^{i}
\end{aligned}
$$


for any $s \geq 1$. We have

$$
\begin{aligned}
& h^{i}\left(\left(y_{0}^{i *}, \omega_{0}^{i}\right)\right)+u^{i}\left(\left(y_{1}^{i *}, \tilde{\omega}_{1}^{i}\right), \ldots,\left(y_{S}^{i *}, \tilde{\omega}_{S}^{i}\right)\right)-h^{i}\left(x_{0}^{i}\right)-u^{i}\left(x_{1}^{i}, \ldots, x_{S}^{i}\right) \\
\geq & \sum_{l \leq M}\left(y_{0 l}^{i *}-x_{0 l}^{i}\right) \frac{\partial h^{i}}{\partial y_{0 l}^{i}}\left(\left(y_{0}^{i *}, \tilde{\omega}_{0}^{i}\right)\right)+\sum_{l>M}\left(\omega_{0 l}^{i}-x_{0 l}^{i}\right) \frac{\partial h^{i}}{\partial y_{0 l}^{i}}\left(\left(y_{0}^{i *}, \tilde{\omega}_{0}^{i}\right)\right) \\
& +\sum_{s} \sum_{l \leq M}\left(y_{s l}^{i *}-x_{s l}^{i}\right) \frac{\partial u^{i}}{\partial y_{s l}^{i}}\left(\left(y_{1}^{i *}, \tilde{\omega}_{1}^{i}\right), \ldots,\left(y_{S}^{i *}, \tilde{\omega}_{S}^{i}\right)\right) \\
& +\sum_{s} \sum_{l>M}\left(\omega_{s l}^{i}-x_{s l}^{i}\right) \frac{\partial u^{i}}{\partial y_{s l}^{i}}\left(\left(y_{1}^{i *}, \tilde{\omega}_{1}^{i}\right), \ldots,\left(y_{S}^{i *}, \tilde{\omega}_{S}^{i}\right)\right) \\
= & \sum_{l \leq M} \mu^{i} \tilde{p}_{0 l}^{*}\left(y_{0 l}^{i *}-\omega_{0 l}^{i}\right)-\sum_{l \leq M} \mu^{i} \tilde{p}_{0 l}^{*}\left(x_{0 l}^{i}-\omega_{0 l}^{i}\right)-\sum_{l>M} \mu^{i} \tilde{p}_{0 l}^{i *}\left(x_{0 l}^{i}-\omega_{0 l}^{i}\right) \\
& +\sum_{s} \lambda_{s}^{i}\left(\sum_{l \leq M} \tilde{p}_{s l}^{*}\left(y_{s l}^{i *}-\omega_{s l}^{i}\right)-\left[\sum_{l \leq M} \tilde{p}_{s l}^{*}\left(x_{s l}^{i}-\omega_{s l}^{i}\right)+\sum_{l>M} \tilde{p}_{s l}^{i *}\left(x_{s l}^{i}-\omega_{s l}^{i}\right)\right]\right) \\
= & -\mu^{i} q^{*} z^{i *}+\mu^{i} q^{*} z^{i}+\sum_{s} \lambda_{s}^{i} R_{s} z^{i *}-\sum_{s} \lambda_{s}^{i} R_{s} z^{i} \geq 0
\end{aligned}
$$

Step 3 We now prove that this equilibrium in $\mathcal{E}_{1}$ is actually an equilibrium for the unbounded economy. Consider an agent $i$.

Assume this agent has consumption good bundles $\left(x_{0}^{i},\left(x_{s}^{i}\right)\right) \in \mathbb{R}_{+}^{L \times(S+1)}$ and asset portfolios $z^{i} \in \mathbb{R}^{J}$ which satisfies, on the one hand,

$$
\begin{aligned}
\sum_{l \leq M} \tilde{p}_{0 l}^{*}\left(x_{0 l}^{i}-\omega_{0 l}^{i}\right)+\sum_{l>M} \tilde{p}_{0 l}^{i *}\left(x_{0 l}^{i}-\omega_{0 l}^{i}\right)+q^{*} z^{i} & \leq 0 \\
\sum_{l \leq M} \tilde{p}_{s l}^{*}\left(x_{s l}^{i}-\omega_{s l}^{i}\right)+\sum_{l>M} \tilde{p}_{s l}^{i *}\left(x_{s l}^{i}-\omega_{s l}^{i}\right) & \leq R_{s} z^{i} \forall s \geq 1
\end{aligned}
$$

and, on the other hand,

$$
U^{i}\left(x_{0}^{i}, x_{1}^{i}, \ldots, x_{S}^{i}\right)>U^{i}\left(x_{0}^{i *}, x_{1}^{i *}, \ldots, x_{S}^{i *}\right)
$$

Let $\lambda \in(0,1)$. Define

$$
\left(x_{0}^{i}(\lambda),\left(x_{s}^{i}(\lambda)\right), z^{i}(\lambda)\right)=\lambda\left(x_{0}^{i *},\left(x_{s}^{i *}\right), z^{i *}\right)+(1-\lambda)\left(x_{0}^{i},\left(x_{s}^{i}\right), z^{i}\right)
$$

For any $\lambda \in(0,1)$, we have

$$
\begin{aligned}
\sum_{l \leq M} \tilde{p}_{0 l}^{*}\left(x_{0 l}^{i}(\lambda)-\omega_{0 l}^{i}\right)+\sum_{l>M} \tilde{p}_{0 l}^{i *}\left(x_{0 l}^{i}(\lambda)-\omega_{0 l}^{i}\right)+q^{*} z^{i}(\lambda) & \leq 0 \\
\sum_{l \leq M} \tilde{p}_{s l}^{*}\left(x_{s l}^{i}(\lambda)-\omega_{s l}^{i}\right)+\sum_{l>M} \tilde{p}_{s l}^{i *}\left(x_{s l}^{i}(\lambda)-\omega_{s l}^{i}\right) & \leq R_{s} z^{i}(\lambda) \forall s \geq 1
\end{aligned}
$$

For $\lambda$ close to one $\left(x_{0}^{i}(\lambda),\left(x_{s}^{i}(\lambda)\right), z^{i}(\lambda)\right) \in X \times Z$. And we have, by the strict concavity of $U^{i}$ :

$$
\begin{aligned}
U^{i}\left(x_{0}^{i}(\lambda), x_{1}^{i}(\lambda), \ldots, x_{S}^{i}(\lambda)\right) & >\lambda U^{i}\left(x_{0}^{i *}, x_{1}^{i *}, \ldots, x_{S}^{i *}\right)+(1-\lambda) U^{i}\left(x_{0}^{i}, x_{1}^{i}, \ldots, x_{S}^{i}\right) \\
& >U^{i}\left(x_{0}^{i *}, x_{1}^{i *}, \ldots, x_{S}^{i *}\right)
\end{aligned}
$$


which is a contradiction.

Hence, $U^{i}\left(x_{0}^{i}, x_{1}^{i}, \ldots, x_{S}^{i}\right) \leq U^{i}\left(x_{0}^{i *}, x_{1}^{i *}, \ldots, x_{S}^{i *}\right)$.

The proof of Theorem 1 is now complete.

\section{Proof of Theorem 2}

Let $\pi \in \Pi$. Consider the budget sets $B^{i}(\pi)$ associated with $\pi$ :

$$
B^{i}(\pi) \equiv\left\{\begin{array}{c}
\left(x^{i}, z^{i}\right) \in X \times Z_{b}: \\
\sum_{l \leq M} p_{0 l}\left(x_{0 l}^{i}-\omega_{0 l}^{i}\right)+\sum_{l>M} p_{0 l}^{i}\left(x_{0 l}^{i}-\omega_{0 l}^{i}\right)+q z^{i} \leq 0 \\
\sum_{l \leq M} p_{s l}\left(x_{s l}^{i}-\omega_{s l}^{i}\right)+\sum_{l>M} p_{s l}^{i}\left(x_{s l}^{i}-\omega_{s l}^{i}\right) \leq p_{s 1} R_{s} z^{i} \forall s \geq 1
\end{array}\right\}
$$

As above, the proof is articulated in three steps.

Step 1

We first consider a two-period economy $\mathcal{F}_{2 b}$ with $I$ countries, $J$ assets and $M$ consumption goods. We define for $s \geq 0$

$$
y_{s}^{i} \equiv\left(y_{s 1}^{i}, \ldots, y_{s M}^{i}\right) \text { and } \tilde{\omega}_{s}^{i} \equiv\left(\omega_{s(M+1)}^{i}, \ldots, \omega_{s L}^{i}\right)
$$

and the following utility functions

$$
k^{i}\left(y_{0}^{i}\right) \equiv h\left(\left(y_{0}^{i}, \tilde{\omega}_{0}^{i}\right)\right) \text { and } v^{i}\left(y_{1}^{i}, \ldots, y_{S}^{i}\right) \equiv u^{i}\left(\left(y_{1}^{i}, \tilde{\omega}_{1}^{i}\right), \ldots,\left(y_{S}^{i}, \tilde{\omega}_{S}^{i}\right)\right)
$$

for any $i$.

Let $\tilde{Y}^{i} \subset \mathbb{R}_{+}^{M \times(S+1)}$ be the projection of

$$
\tilde{Y} \equiv\left\{\left(x_{s}^{i}\right) \in \mathbb{R}_{+}^{I \times M \times(S+1)}: \sum_{i}\left(x_{s l}^{i}-\omega_{s l}^{i}\right) \leq 0 \forall l \leq M \text { and } \forall s \geq 0\right\}
$$

on the $i$-th component. Let $Y$ be a closed ball of $\mathbb{R}^{M \times(S+1)}$ containing all the $\tilde{Y}^{i}$ in its interior. We consider $Y$ as the consumption set. For the economy $\mathcal{F}_{2 b}$, the set of prices for both periods is $\tilde{\Pi} \equiv Q \times \Pi_{1}$ with

$$
\begin{aligned}
Q & \equiv\left\{q \in \mathbb{R}^{J}:\left|q_{j}\right| \leq 1 \forall j\right\} \\
\Pi^{1} & \equiv\left\{\pi^{1} \in \mathbb{R}^{M \times(S+1)}:\left|p_{s l}\right| \leq 1 \forall l \leq M \text { and } \forall s \geq 0\right\}
\end{aligned}
$$

We denote the prices vector by $\left.\tilde{\pi}=\left(q, \pi^{1}\right)\right) \in Q \times \Pi^{1}$ and the set of $\tilde{\pi}$ with strictly positive components by $\tilde{\Pi}_{++}$.

Each representative agent of a country purchases consumption goods and assets in the first period and consumes in the second period. Given the system of prices $\tilde{\pi} \in \tilde{\Pi}$, an agent $i$ computes her optimal demands for assets and consumption goods solving the following program:

$$
\begin{aligned}
& \max k^{i}\left(y_{0}^{i}\right)+v^{i}\left(y_{1}^{i}, \ldots, y_{S}^{i}\right) \\
& \text { subject to } \\
& \sum_{l \leq M} p_{0 l}\left(y_{0 l}^{i}-\omega_{0 l}^{i}\right)+q z^{i} \leq 0 \text { (first period) } \\
& \sum_{l \leq M} p_{s l}\left(y_{s l}^{i}-\omega_{s l}^{i}\right) \leq p_{s 1} R_{s}^{i} z^{i} \text { (second period) }
\end{aligned}
$$


for any $s \geq 1$.

An equilibrium of $\mathcal{F}_{2 b}$ is a list of prices and allocations $\left(\tilde{\pi}(b),\left(z^{i}(b),\left(y_{s}^{i}(b)\right)_{s \geq 0}\right)_{i}\right)^{*}$ such that

(1) $\tilde{\pi}^{*}(b) \in \tilde{\Pi}_{++}$,

(2) $\sum_{i} z^{i *}(b)=0, z^{i *}(b) \in Z_{b}$ for any $i$

(3) $\sum_{i}\left(y_{s l}^{i *}(b)-\omega_{s l}^{i}\right)=0$ for any $l \leq M$ and any $s \geq 0$,

(4) $\left(z^{i}(b),\left(y_{s}^{i}(b)\right)_{s \geq 0}\right)^{*}$ is the optimal demand given the prices $\tilde{\pi}^{*}(b)$ for any $i$.

It is proved in Cass (1984), Florenzano (1999), that there exists an equilibrium of $\mathcal{F}_{2 b}$, $\left(\tilde{\pi}(b),\left(z^{i}(b),\left(x_{s}^{i}(b)\right)_{s \geq 0}\right)_{i}\right)^{*}$ which satisfies (with $\left.\tilde{\pi}^{*}(b)=\left(q^{*}(b), \pi^{* 1}(b)\right) \in Q \times \Pi^{1}\right)$

- $q^{*}(b)=\sum_{r} p_{s 1}^{*} R_{s}$

- this equilibrium is a Cass equilibrium defined as follows

$-x^{1 *}(b)$ solves the problem $\left\{\max u^{1}\left(x_{0}^{1}, x^{1}, 1, \ldots, x_{S}^{1}\right): \pi^{* 1}(b) \cdot\left(x^{1}-\omega^{1}\right) \leq 0\right\} \quad$ the constraint is Arrow-Debreu contingent)

- $\left(x^{i *}(b), z^{i *}(b)\right)$ for $i \geq 2$ solve

$$
\begin{aligned}
& \max u^{i}\left(x_{0}^{i}, x_{1}^{i}, \ldots, x_{S}^{i}\right) \\
& \sum_{l \leq M} p_{0 l}^{* 1}\left(x_{0}^{i}-\omega_{0 l}^{i}\right)+q^{*}(b) \cdot z^{i} \leq 0 \\
& \sum_{l \leq M} p_{s l}^{* 1}\left(x_{s}^{i}-\omega_{s l}^{i}\right) \leq p_{s 1}^{*} R_{s} \cdot z^{i}, l ; s=1, \ldots, S
\end{aligned}
$$

- $\left\|\pi^{* 1}(b)\right\|=1$

- $\pi^{* 1}(b)>>0$.

Moreover, any Cass equilibrium $\left(\tilde{\pi}^{* 1},\left(x^{i *}\right)_{i \geq 1},\left(z^{i *}\right)_{i \geq 2}\right)$ provides actually an equilibrium of the economy $\mathcal{F}_{2 b}$ with $z^{1 *}=-\sum_{i \geq 2} z^{i *}$.

We now consider a sequence of real numbers $\left\{b^{n}\right\}$ which converges to $+\infty$ when $n$ goes to infinity. We can suppose the sequence $\left\{\left(\tilde{\pi}^{1 *}\left(b^{n}\right),\left(x^{* i}\left(b^{n}\right)\right)_{i \geq 1}\right)\right\}$ converges to $\left(\bar{\pi}^{1},\left(\bar{x}^{i}\right)_{i \geq 1}\right)$. Since $\left\|\bar{\pi}^{1}\right\|=1$, the Arrow-Debreu budget set of agent 1 associated with $\bar{\pi}^{1}$ has a non-empty interieur. This implies that $\bar{x}^{1}$ is optimal in the Arrow-Debreu budget set associated with prices $\bar{\pi}^{1}$. Since the utility function $u^{1}$ is strictly increasing, we have $\bar{\pi}^{1}>>0$. In particular, $\bar{p}_{s 1}>0$ and hence, the matrix $\left(\bar{\pi}_{s 1}^{1} R_{s}\right)$ has rank $J$. We claim that the sequences $\left\{\left(z^{i *}\left(b^{n}\right)\right)_{i}\right\}$ are uniformly bounded. Assume the contrary: there exists a subsequence $\left\|z^{i *}\left(b^{\nu}\right)\right\|$ which converges to infinity. Define $\zeta^{\nu}=\frac{z^{i *}\left(b^{\nu}\right)}{\left\|z^{i *}\left(b^{\nu}\right)\right\|}$. Then $\zeta^{\nu}$ converges to some $\zeta$ in the unit sphere of $\mathbb{R}^{J}$. Since, for all $\nu$, all $s \geq 1$ :

$$
\frac{p_{s}^{1 *}\left(b^{\nu}\right) \cdot\left(x_{s}^{i *}\left(b^{\nu}\right)-\omega_{s}^{i}\right)}{\left\|z^{i *}\left(b^{\nu}\right)\right\|}=p_{s 1}^{*}\left(b^{\nu}\right) R_{s} \cdot \zeta^{\nu}
$$

passing to the limit we get:

$$
0=\bar{p}_{s 1} R_{s} \cdot \zeta
$$


This implies $\zeta=0$ since the rank of the matrix $\left(\bar{\pi}_{s 1}^{1} R_{s}\right)$ is $J$. That is a contradiction since $\zeta \neq 0$.

We can therefore assume that $z^{i *}\left(b^{n}\right)$ converges to $\bar{z}^{i}$, for any $i$. Define $\bar{z}^{1}=-\sum_{i>2} \bar{z}^{i}$. Define also $\bar{q}=\sum_{s} \bar{p}_{s}^{1} R_{s}$. It is easy to check that $\left(\bar{p}^{1}, \bar{q},\left(\bar{x}^{i}\right)_{i},\left(\bar{z}^{i}\right)_{i}\right)$ is an equilbrium for economy $\mathcal{F}_{2}$.

Step 2 To obtain an equilibrium for the initial economy $\mathcal{E}_{2}$, we proceed as in Step 2 of Case 1 replacing $R_{s}$ by $\bar{p}_{s 1}^{1} R_{s}$.

Step 3

Proceed and in Case 1.

\section{References}

[1] Akram, Q.F., D. Rime and L. Sarno (2008). Does the law of one price hold in international financial markets? Evidence from tick data. Working Papers of the Research Department 2008/19, Norges Bank.

[2] Bosi S., P. Fontaine and C. Le Van (2016). Interest rates parity and no arbitrage as equivalent equilibrium conditions in the international financial assets and goods markets. Mathematical Social Sciences 82, 26-36.

[3] Bosi S., P. Fontaine and C. Le Van (2017). How to determine exchange rates under risk neutrality: a note. Economics Letters 157, 92-96.

[4] Cass D. (1984). Competitive equilibrium with incomplete markets, CARESS Working paper 84-09, University of Pennsylvania.

[5] Chen Z. and P.J. Knez (1995). Measurement of market integration and arbitrage. Review of Financial Studies 8, 287-325.

[6] Coeurdacier N. and H. Rey (2013). Home bias in open economy financial macroeconomics. Journal of Economic Literature 51, 63-115.

[7] Dana R-A. and M. Jeanblanc-Picqué (2003). Financial Markets in Continuous Time. Springer Finance Textbooks

[8] Debreu G. (1959). Theory of Vaue. An Axiomatic Analysis od Economic Equilibrium. New Haven and London, Yale University Press.

[9] Florenzano M. (1999). General equilibrium of financial markets: An introduction. Working Paper MSE 1999.76, University of Paris 1.

[10] Hart O. (1974). On the existence of an equilibrium in a securities model. Journal of Economic Theory 9, 293-311.

[11] Hassan T.A. (2013). Country size, currency unions, and international asset returns. Journal of Finance 68, 2269-2308. 
[12] Hassan T.A. and R.C. Mano (2017). Forward and spot exchange rates in a multicurrency world. Fama-Miller Working Paper, Chicago Booth Research Paper 15-02.

[13] Isard P. (2006). Uncovered Interest Parity. IMF Working Paper 06/96.

[14] Lamont O.A. and R.H. Thaler (2003). The law of one price in financial markets. Journal of Economic Perspectives 17, ,191-202.

[15] Lewis K.K. (2011). Global asset pricing. Annual Review of Financial Economics 3, $435-466$.

[16] Martin I. (2013). The forward premium puzzle in a two-country world. NBER Working Papers 17564.

[17] Obstfeld M. and K. Rogoff (2000). The six major puzzles in international macroeconomics: Is there a common cause? NBER Macroeconomics Annual 15, 339-412.

[18] Pippenger, J. and L. Phillips (2007). Strictly speaking, the law of one price works in commodity markets. Economics Working Paper Series 16-07, Department of Economics, University of California Santa Barbara.

[19] Protopapadakis A. and H.S. Stoll (1983). Spot and futures prices and the law of one price. Journal of Finance 5, 1431-1455.

[20] Protopapadakis A. and H.S. Stoll (1986). The law of one price in international commodity markets: a reformulation and some formal tests. Journal of International Money and Finance 5, 335-360.

[21] Sarno L., P. Schneider and C. Wagner (2012). Properties of foreign exchange risk premiums. Journal of Financial Economics 105, 279-310.

[22] Uppal R. (1993). A general equilibrium model of international portfolio choice. Journal of Finance 48, 529-553.

[23] van Wincoop E. and F.E. Warnock (2010). Can trade costs in goods explain home bias in assets? Journal of International Money and Finance 29, 1108-1123.

[24] Vasilyev D., V. Busygin and S. Busygin (2017). Testing and interpreting uncovered interest parity in Russia. Russian Journal of Economics 3, 158-173. 